\title{
The effect of inflation rate on the cost of medical waste management system
}

\author{
Maria Jolanta Walery ${ }^{1, *}$ \\ ${ }^{1}$ Bialystok University of Technology, Faculty of Civil and Environmental Engineering, \\ ul. Wiejska 45E, 15-351 Bialystok, Poland
}

\begin{abstract}
This paper describes the optimization study aimed to analyse the impact of the parameter describing the inflation rate on the cost of the system and its structure. The study was conducted on the example of the analysis of medical waste management system in north-eastern Poland, in the Podlaskie Province. The scope of operational research carried out under the optimization study was divided into two stages of optimization calculations with assumed technical and economic parameters of the system. In the first stage, the lowest cost of functioning of the analysed system was generated, whereas in the second one the influence of the input parameter of the system, i.e. the inflation rate on the economic efficiency index (E) and the spatial structure of the system was determined. With the assumed inflation rate in the range of 1.00 to 1.12 , the highest cost of the system was achieved at the level of PLN 2022.20/t (increase of economic efficiency index E by ca. $27 \%$ in comparison with run 1 , with inflation rate $=1.12$ ).
\end{abstract}

\section{Introduction}

Optimization models can assist in ensuring that investment strategies will be economically feasible in the optimal decision-making in deciding their choice. Good decision-making is done based on experience, trial and error or comparison between different options of the integrated model of waste management [1-3].

New investments in waste management system are needed due to a number of factors including continuously increasing waste amounts, legal, political and economical demands for efficient utilization of the waste or energy production, and decommissioning of existing waste treatment facilities due to age and stricter environmental regulation $[4,5]$.

Various economic optimization models for waste treatment have been developed which focus on different parameters. Models focusing on transport, on energy production, have also been developed as well as models which take into account the economies of scale environmental impact, material recovery and social costs. Finally, models combining different criteria for selection of waste treatment methods in multi criteria analysis have been developed [6-8].

\footnotetext{
* Corresponding author: m.walery@pb.edu.pl
} 
A thorough updated review of the existing models is presented and the main and the crucial parameters to take into account when assessing the economic performance of waste management system.

$\mathrm{Yu}$ et al. [9] conducted a study on optimization of the long-term performance of municipal solid waste management system in the form of a bi-targeted mathematical model. In this paper, a linear and dynamic programming bi-targeted model is proposed for decision-making on supporting long-term operations of municipal solid waste management system. The proposed mathematical model simultaneously deals with calculation of the economic productivity and environmental pollution from the municipal solid waste management system within several time periods. The proposed model has been calculated and solved by Lingo Software. The proposed model provided an effective solution for the long-term operational planning of the municipal solid waste management system [10].

Ravindra et al. [11] focused on the analysis of municipal solid waste management system and the methods to minimizing it in Chandigarh in India. The information was collected from the involvement of various public-private stakeholders through interviews and information of the registry related to transportation and solid waste disposal. This study has emphasized that the solid waste recycling system in this city is poor, where negligence of this important section has followed negative consequences. Thus, for environmentallyfriendly solid waste management systems, a serious decision-making process and adjustment of operational activities are required. Further, based on system analysis approach the study proposes options for the improvement in current waste management practices in Chandigarh, which could also be adopted by other cities in developing world to reduce the adverse impact of solid waste management on environment and human health.

Kollikkathara et al. [12] presented a system dynamics approach designed for planning for sustainable municipal solid waste management. It attempts to address some of these issues by fitting a model framework for Newark urban region in the US, and running a forecast simulation. The dynamic system developed in this study incorporates the complexity of the waste generation and management process to some extent which is achieved through a combination of simpler sub-processes that are linked together to form a whole. The impact of decision options on the generation of waste in the city, on the remaining landfill capacity of the state, and on the economic cost or benefit actualized by different waste processing options are explored through this approach.

Shmelev [13] investigated three different approaches to the spatial-temporal analysis of the municipal solid waste management systems are used together, namely a life cycle inventory analysis, which helps to identify emission patterns within the municipal solid waste management systems, a multi-criteria optimisation approach, which helps to find compromise solutions among environmentally and economically preferred options, and a geographic information systems approach, which provides a tool for identifying waste management facilities, transportation environmental and social impacts; it also gives an analysis of environmental impacts on valuable ecosystems. The approach provides a new perspective for the analysis of municipal solid waste management systems on the regional scale. The principal novelty of the proposed complex the municipal solid waste strategic management model is an integration of the different types of data: geographical, environmental and economic, using relational database technology.

Soltani et al. [14] focused on the analysis of decision-making in Municipal Solid Waste Management (MSWM) problems such as finding proper waste treatment locations or strategies often requires multiple stakeholders such as government, municipalities, industries, experts, and/or general public to get involved. Multi-criteria Decision Analysis (MCDA) is the most popular framework employed in previous studies on MSWM; MCDA methods help multiple stakeholders evaluate the often conflicting criteria, communicate their different preferences, and rank or prioritize MSWM strategies to finally agree on some 
elements of these strategies and make an applicable decision. Results of this study show that AHP is the most common approach in consideration of multiple stakeholders and experts and governments/municipalities are the most common participants in these studies.

Shi et al. [15] investigated the a Mixed Integer Linear Programming model with minimizing costs for medical waste reverse logistics networks. The total costs for reverse logistics include transportation cost, fixed cost of opening the collecting centers and processing centers and operation cost at these facilities over finite planning horizons. An improved genetic algorithm method with a hybrid encoding rule is used to solve the proposed model. The efficiency and practicability of the proposed model is validated by an application to an illustrative example dealing with medical waste returned from some hospitals to a given manufacture.

Alshraideh, Qdais [16] focused on the analysis of medical system in Jordan. In this paper, a route scheduling model is proposed to minimize the total travel distance which in turn minimizes transportation cost and reduces emissions. The proposed model takes into account the capacity of trucks, number of visits per week, timing between visits along with the service level required by the hospitals. An optimal routing schedule was found and verified.

\section{Research methodology}

This paper uses optimization model of the export and disposal of municipal waste [3], as well as a computer program MRGO (Model of Regional Waste Management), which is its implementation. It has been verified by the author and adapted to the needs of the proposed model to optimize the removal and disposal of medical waste.

Medical waste due to the very diverse morphological composition and their potential infectious and toxic properties require a specific action depending on the degree of risk to humans and the environment. Medical waste management system is very different from municipal waste management system in the principles of collection of medical waste at source, storage, means and conditions of transport with regard to the provisions of the European Agreement ADR or processing systems and waste disposal. With this in mind the author has reviewed the structure of the mathematical model MRGO+[3] with a four-element system, and between themselves correlation to the system three-piece, in which the following system objects: source objects (hospitals), intermediate objects (medical waste incinerators) and final facilities located in the area of medical waste incinerator, i.e. the place for the temporary detention of post-process waste from waste incineration process. Such a solution in functioning of medical waste management enabled the achievement of the overall optimization of the system, relating to the effects and costs of servicing the region, not only in terms of local optimization, e.g. in a single gmina (PL administrative district). Therefore, it is extremely important to raise funds for the development of a cost-efficient and modern waste management system, in terms of technical and technological solutions as well as environmental protection requirements.

The structure of functioning of medical waste management system adopted by the author, was further verified in terms of the system functional division of transport operational tasks. The infectious medical waste management system does not include waste dumping mode, which normally is capable of a 2-3-fold compaction of waste in lorries of large capacity, minimum several $\mathrm{m}^{3}$. As stated in the Act on Waste Management, infectious waste is not subject to segregation and composting due to its infectious properties, hence the medical waste management system is not composed of two-stage transportation and redistribution stations (waste processing and distribution to various sites of treatment). For this reason, the author verified multistage transport to the advantage of a single-stage, direct system and in this perspective the elements of the system (stages of activity) are as 
follows:

- source forming regions (collection) of medical waste,

- route export of waste from the source areas of collection to an indirect facility in which there are waste treatment processes, independent or combined into a pre-technological and secondary process line,

- routes for post-processing waste disposal from the intermediate object to the end-object, where waste undergoes final treatment processes.

In addition, waste landfill storage - one of the methods of waste disposal commonly used in Poland is not applied in the infectious medical waste management system. Only post-process waste may be disposed of in landfills, and only marked as hazardous type. Therefore, the author introduced the concept of a "post-process thermal treatment waste temporary storage", i.e. adequately protected and separated area by the medical incineration plant, where post-treatment waste is temporarily stored for up to 3 years in accordance with Polish laws, and then exported to a hazardous waste landfill. Therefore, the costs of transport and storage of waste will be incurred once every three years, which was included in this stage of implementation of transport activities proposed by the author of the cost optimization model.

\subsection{Case study}

In this paper, the optimization model of the export and disposal of medical waste is presented in the dynamic version, taking into account expected changes of input and output parameters of the waste management system as well as its status in given periods of time.

A model region in north-eastern Poland, i.e. the Podlaskie Province, which can be considered representative for other regions, was chosen for the optimization research. The input data, necessary to describe the proposed variations in medical waste management system, has been collected and compiled in the course of analytical and factual study. Optimization study which was based on real data for both technical parameters and economic quantities, allows generalise the results and their implication for other similar regions.

The aim of the study was to analyse the impact of the parameter describing the degree of reduction in the amount of medical waste in the combustion process (wwp) and the unit cost of transport of medical waste $\left(\mathrm{K}_{\mathrm{ij}}\right)$ on the value of the economic efficiency index $(\mathrm{E})$. With the assumed technical and economical parameters of the system the operating range of tests, performed as part of the optimization study was divided into two stages. In the first stage, the lowest cost of operation of the system was calculated, while the second stage resulted in describing the impact of input parameters of the system, i.e. the degree of reduction in the amount of medical waste in the incineration of waste and the unit cost of transport of waste on the economic efficiency index and spatial structure of the system (set of system facilities and related transportation network).

18 sources of waste generation and accumulation (hospitals) within the studied area of the Podlaskie Province were selected for the analysis after taking into account the above mentioned assumptions and environmental conditions. The study also included: four intermediate objects (medical waste incinerators), respectively: IF1 (Suwalki), IF2 (Lomza), IF3 (Bialystok) and IF4 (Hajnowka), where pyrolytic decomposition process of waste will take place, and four end objects (respectively FF1, FF2, FF3, FF4) - areas for temporary storage of post-process waste from the incineration process located in the area of waste incineration facility. The model did not include restrictions on the capacity of intermediate and end objects.

The scope of operational research carried out in the framework of the optimization study was divided into successive stages in order to present options of the proposed model: 
Stage I - includes optimization calculations, assuming fixed technical and economic parameters. Sequence 1, made in this stage, was also a comparative course - a benchmark for other solutions and obtained results to compare.

Stage II - included a number of additional runs aimed at determining the impact of the model input parameters of the system on the indicator of expenses of economic efficiency (E) and the spatial structure of the system (system location of objects and their associated waste disposal routes).

The following input data were taken into account:

- economic parameters describing the system (waste transport unitary costs, inflation and discount rate),

- economic parameters describing the objects of the system (capital and operating costs), - the size reduction of medical waste in the system of indirect objects expressed in the form of the output factor of the process - wwp [\%],

- the planned time horizon [ $\mathrm{t}]$, (duration of model process).

The data relating to the costs of transport, investments and operation of the system objects, necessary for optimisation calculations, derived from existing plants, located in the model region. The calculation was performed by the unit cost of the work presented in Biedugnis et al. [3] taking into account the current prices and fees. The cost of medical waste removal from the source unit to the disposal site, with the adopted technical and operational conditions is $\mathrm{K}_{\mathrm{ij}}=$ PLN 9.57, and when expressed in unit cost of 1 ton of transport per 1 minute $(\mathrm{k})=$ PLN 1.33/t/min.

The economic efficiency calculations of the method were presented in the work by Biedugnis et al. [3] whose dynamic model related to inflation and discounting of the annual capital and operating costs in each model period. Transport costs are also discounted and adjusted for inflation.

Finding the best solution from the point of view of economic efficiency indicator was set as a priority. The above mentioned criterion takes into account both the selection of waste treatment technologies, as well as search for the best relationship between the location of objects used and the associated waste transport route network, depending on the amount of waste transported in each model periods.

\section{Results and discussion}

Calculations were carried out in the following runs:

Stage I - run 1 - the run like in the solution with the following parameters: duration of model period, respectively $\mathrm{t} 1=5$ and $\mathrm{t} 2=15$ years, the unitary cost of transportation of medical waste in the first and second model period, respectively, 1.33 and $0.44 \mathrm{PLN} / \mathrm{t} / \mathrm{min}$, the level of reduction of medical waste in the intermediate facilities expressed as a coefficient of the process output, wwp $=10 \%$.

Stage II - in runs 2-5 - the impact of changes in the inflation rate on the cost of the system and its spatial structure was examined. The inflation rate has a significant impact on the cost of operating the system and, consequently, the change in the economic efficiency index (E).

As a result of optimization calculations for the course 1 (Stage I) of the pre-established model system of the 26 facilities (18 - the source of the medical waste, 4 - incineration, 4 - storage of hazardous waste, 55 - possible routes for waste transport), the was a number of facilities selected in model periods I and II: $3 / 3$ incinerators, $3 / 3$ of the landfills and $21 / 21$ waste transport routes, in consequence minimizing the cost of the system. Process levels in intermediate and final facilities in each model period for Stage I are presented in Table 1. 
Table 1. The level of processing activities of intermediate and final objects for the $1^{\text {st }}$ run [ton/year].

\begin{tabular}{|c|c|c|c|}
\hline $\begin{array}{c}\text { System } \\
\text { facilities }\end{array}$ & Process & $\begin{array}{c}\text { Processing } \\
\text { activity level } \\
\text { [t/year] }\end{array}$ & $\begin{array}{c}\text { Duration of model } \\
\text { studies } \\
\text { I=5 years, II=15 years }\end{array}$ \\
\hline IF1 & incineration & 140.400 & I \\
\hline IF1 & incineration & 148.800 & II \\
\hline IF2 & incineration & 210.400 & I \\
\hline IF2 & incineration & 222.400 & II \\
\hline IF3 & incineration & 434.400 & I \\
\hline IF3 & incineration & 450.900 & II \\
\hline FF1 & storage & 14.040 & I \\
\hline FF1 & storage & 14.880 & II \\
\hline FF2 & storage & 21.040 & II \\
\hline FF2 & storage & 22.240 & I \\
\hline FF3 & storage & 43.440 & II \\
\hline FF3 & storage & 45.090 & \\
\hline
\end{tabular}

For runs 2, 3 and 4 (Table 2) with the assumed inflation rate (1.00-1.08) - a scheme of location of system objects, quantity of transported waste and associated transport routes are the same as in the case of run 1.

The increase in the inflation rate in the range from 1.00 to 1.08 results in an increase in the economic efficiency index (E) by ca. 23\% from PLN 1,390.60/t to PLN 1,707.20/t, with the assumed duration of the first and second model periods $\mathrm{t} 1=5$ years and $\mathrm{t} 2=15$ years and wwp $=10 \%$.

In run 5, with the assumed inflation rate $=1.12$, the transport system was changed in particular model periods. There were not only changes in the amount of waste transported to intermediate plants (incineration plants), but also the time (model period) in which these changes took place. Hence, there were two additional transport activities - transport routes of waste from the source of waste to the intermediate site, i.e. in the first model period the vast majority of waste from Augustow (16,300 t/year) was transported to the incinerator in Bialystok. The remaining amount of waste produced $(6,200 \mathrm{t} /$ year) was transferred to an incineration plant in Suwalki. In the second model period, the waste in total $(23,600 \mathrm{t} / \mathrm{year})$ was transported to the incinerator in Bialystok instead of to the incineration plant in Suwalki. Another additional transport activity occurred in the case of transportation of waste from Dabrowa Bialostocka, in the first and second model year, to the incineration plant in Bialystok and not to Suwalki, where the amount of transported waste did not change.

Table 2 presents the levels of processing activity in intermediate and final objects in the first and second model periods for run 5 .

In run 5 (inflation rate $=1.12$ ) the highest economic efficiency index was obtained at the level of 2022.20 PLN/t (increase of $E$ by about $27 \%$ in relation to run 1 ).

Figure 1 shows the values of economic efficiency index E for runs 2-5 depending on the inflation rate. The increase in inflation leads to an exponential increase in E. 
Table 2. The level of processing activities of intermediate and final objects for the $5^{\text {nd }}$ run [ton/year] within the model area.

\begin{tabular}{|c|c|c|c|}
\hline $\begin{array}{c}\text { System } \\
\text { facilities }\end{array}$ & Process & $\begin{array}{c}\text { Processing } \\
\text { activity level } \\
\text { [t/year] }\end{array}$ & $\begin{array}{c}\text { Duration of model } \\
\text { studies } \\
\text { I=5 years, II=15 years }\end{array}$ \\
\hline IF1 & incineration & 116.900 & I \\
\hline IF1 & incineration & 116.900 & II \\
\hline IF2 & incineration & 210.400 & I \\
\hline IF2 & incineration & 222.400 & II \\
\hline IF3 & incineration & 457.900 & I \\
\hline IF3 & incineration & 482.800 & II \\
\hline FF1 & storage & 11.690 & I \\
\hline FF1 & storage & 11.690 & II \\
\hline FF2 & storage & 21.040 & II \\
\hline FF2 & storage & 22.240 & I \\
\hline FF3 & storage & 45.790 & II \\
\hline FF3 & storage & 48.280 & \\
\hline
\end{tabular}

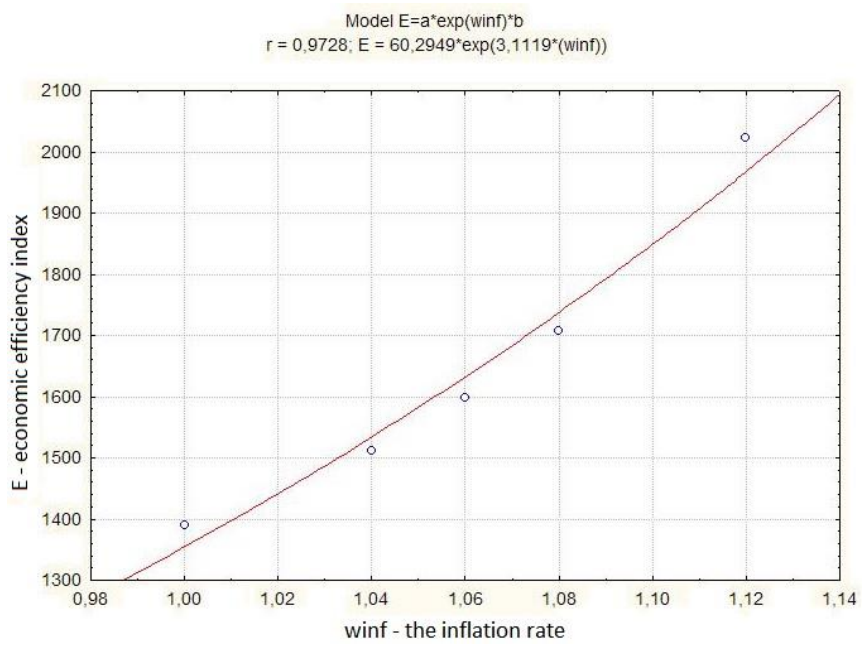

Fig. 1. Correlation of economic efficiency index (E) and inflation rate.

\section{Conclusions}

Taking into account the inflation rate causes a significant change in the system's operating costs and consequently a change in the economic efficiency index (E). It does not, however change the spatial structure of the system, i.e. the location scheme of the system objects, the quantity of waste transported and the associated waste transport routes. Only for the case with the assumed inflation index $=1.12$, the pattern of transport activity changed in particular model periods. There were not only changes in the amount of waste transported to intermediate plants (incineration plants), but also the time (model period) in which these changes took place. With the assumed inflation rate in the range of 1.00 to 1.12 , the highest cost of the system was achieved at the level of 2022.20 PLN / t (increase of economic efficiency index E by ca. $27 \%$ in comparison with run 1, and inflation rate $=1.12$ ).

The increase in the inflation rate is accompanied by an increase in the economic efficiency ratio (E), which can be described by the following correlation: 


$$
\mathrm{E}(\text { winf })=60.2949 \cdot \mathrm{e}^{3.1119 \cdot(\text { winf })}[\mathrm{PLN} / \mathrm{t}]
$$

The research was carried out within the scope of work No. S/WBIIŚ /2/14 and financed from the resources for science of Ministry of Science and Higher Education.

\section{References}

1. M. Chaerul, M. Tanaka, A.V. Shekdar, Waste Manage. 28 (2008)

2. N.O. Eriksson, M. Bisaillon, Waste Manage. 31 (2011)

3. S. Biedugnis, P. Podwójci, M. Smolarkiewicz, Optimization of municipal waste management in micro and macro-region scale (PAN, Warsaw, 2003)

4. A. Moreo, F.J. DeMicco, L. Xiong, J Qual. Assurance Hosp. Tour. 10, 1 (2009)

5. A. Skordilis, Resour. Conserv. Recy. 41 (2004)

6. G. Ghiani, D. Laganà, E. Manni, R. Musmanno, D. Vigo, Comput. Oper. Res. 44 (2014)

7. N. Juul, M. Münster, H. Ravn, M.L. Söderman, Wastes: Solut., Treat. and Opp. (2011)

8. S.E. Shmelev, J.R. Powell, Ecol. Econ. 59, 1 (2006)

9. H. Yu, W.D. Solvang, S. Li, J. Eng. Environ. 6, 2 (2015)

10. M.A. Shirazi, R. Samieifard, A.M. Abduli, B. Omidvar, J. Environ. Health Sci. Eng. 14, 8 (2016)

11. K. Ravindra, K. Kaur, S. Mor, J. Clean. Prod. 89 (2015)

12. N. Kollikkathara, H. Feng, D. Yu, Waste Manage. 30, 11 (2010)

13. S.E. Shmelev, Ecol. Econ. 195-224 (2012)

14. A. Soltani, K. Hewage, B. Reza, R. Sadiq, Waste Manage. 35 (2015)

15. L. Shi, H. Fan, P. Gao, H. Zhang, Adv. Comput. Intelligence, 40-52 (2009)

16. H. Alshraideh, H.A. Qdais, J. Mater. Cycles Waste Manag. 1-11 (2016) 